\title{
APRENDENDO COM O CONSTRUÍDO: APO EM UNIVERSIDADES PÚBLICAS - UM ESTUDO DE CASO
}

\author{
OLIVEIRA, Haluane Santana de \\ Universidade de São Paulo, e-mail: haluane.oliveira@usp.br \\ OLIVEIRA, Fabiana Lopes de \\ Universidade de São Paulo, e-mail: floliveira@usp.br
}

\begin{abstract}
RESUMO
Projetar universidades públicas é desafiador e é essencial desenvolver ferramentas que ajudem a elaborar projetos com melhor desempenho para essas instituições. E para isso, a avaliação de edifícios já em uso pode ser uma importante fonte de dados. Esse trabalho busca analisar edifícios universitários, desenvolvendo instrumentos para avaliá-los que podem também serem aplicados em construções para o mesmo fim, utilizando procedimentos metodológicos da Avaliação Pós-Ocupação (APO). Nesse artigo, são abordados resultados parciais referentes a aplicação de alguns desses instrumentos em um estudo de caso (edifício universitário). Pretende-se assim identificar possibilidades de melhoria para os locais analisados, além de criar parâmetros de avaliação e diretrizes de projeto para novas edificações.
\end{abstract}

Palavras-chave: Edifícios Públicos, Edifícios Universitários, Avaliação de Desempenho, Avaliação Pós-Ocupação - APO.

\section{ABSTRACT}

Designing public universities is challenging. It is essential to develop tools to support the design of better performance projects. So, to evaluate buildings in use can be an important data source. This work seeks to analyze university buildings, and develop evaluation tools, in the context of the institution case study, but that also applicable buildings with the same use. For this, it uses methodological procedures of the Post-Occupancy Evaluation (POE). In this paper, partial results are addressed concerning the application of some of these instruments in a case study (a university building). Thus, it is intended to identify improvement possibilities in the analyzed places, besides to creating evaluation parameters and design guidelines for new buildings.

Keywords: Public buildings, University buildings, Building Performance, POE - Post-occupancy Evaluation.

\section{INTRODUÇÃO}

Para projetar instituições públicas de ensino, é preciso traduzir para o projeto anseios da comunidade usuária e da população em geral. Existem diversos normativos, controles, legislações, que visam a segurança e transparência no uso do recurso público, mas que podem tornar o processo burocrático e restrito.

No caso das universidades públicas, seus edifícios abrigam programas variados e complexos (ambientes didáticos; instalações de pesquisa, em diversas áreas do conhecimento, com demandas específicas; e ambientes para extensão, incluindo aqueles usados pela população externa). Também costumam ser

OLIVEIRA, H. S.; OLIVEIRA, F. L. Aprendendo com o construído: APO em universidades públicas um estudo de caso. In: SIMPÓSIO BRASILEIRO DE QUALIDADE DO PROJETO NO AMBIENTE CONSTRUÍDO, 6., 2019, Uberlândia. Anais... Uberlândia: PPGAU/FAUeD/UFU, 2019. p. 1014-1023. DOI https://doi.org/10.14393/sbqp19093. 
edifícios que dialogam com a vizinhança imediata e regional, como referência de espaço público - aspecto que também deve ser considerado em seus projetos.

Além disso, é comum nessas instituições uma pressão por crescimento, aumento de vagas, modernização. O uso universitário é um programa dinâmico, constantemente ligado à inovação. Por isso, é alta a demanda por alterações na infraestrutura para acompanhar o desenvolvimento acadêmico (MARTINS et a.l, 2014). Enfrenta-se então, um impasse entre um rápido atendimento às demandas - com grandes necessidades de mudanças e intervenções - e um processo muitas vezes moroso e burocrático. Para tal, nem sempre o órgão público dispõe de equipes técnica e administrativa estruturadas para enfrentar essas situações.

Por essa razão é essencial pesquisar e adotar estratégias que contribuam para a superação dessas dificuldades, buscando a eficiência e a satisfação das demandas nos projetos públicos.

No caso das Universidades Federais, além de considerar as particularidades enfrentadas por órgãos públicos na administração de suas infraestruturas, e dessas especificidades relacionadas ao programa, cabe lembrar a adesão das mesmas no Programa REUNI (Reestruturação e Expansão das Universidades Federais) do governo federal, instituído pelo Decreto $n^{\circ} 6.096$, de 24 de abril de 2007, vigente aproximadamente entre 2007 e 2013, que visava a ampliação de vagas e maior alcance territorial das universidades federais no país, com grande aporte de recursos em expansão (novos campi, novas instituições, novos cursos) e infraestrutura (BRASIL, 2011).

Nesse contexto houve uma rápida ampliação na infraestrutura das Universidades, e se deu início a construções e reformas em várias instituições, visando atingir as metas do programa. No entanto, considerando as já citadas especificidades do processo de construção pública, tal expansão encontrou entraves ao longo de seu desenvolvimento que agora, alguns anos depois, podem ter seus resultados melhor verificados nessas instituições.

Avaliar esses edifícios, construídos em um cenário atípico, pode ser fundamental para identificar "erros e acertos", a eficácia de seus projetos e construções, buscando a melhoria nos processos de gestão, planejamento e projeto, dos atuais e futuros edifícios de universidades federais.

Dessa forma, a Avaliação Pós-Ocupação (APO) se apresenta como uma ferramenta útil para subsidiar tanto os diversos processos de gestão e ampliação das infraestruturas das instituições públicas. Assume duas vertentes, aliando uma análise mais técnico-construtiva, que abrange o desempenho do edifício e de seus sistemas, à uma mais voltada a percepção e a satisfação dos usuários, (ORNSTEIN, 2011). Questões sobre comportamento, interações pessoas-ambientes, adequação ao uso e bem-estar são consideradas nesse tipo de avaliação, buscando-se um diagnóstico completo, capaz de orientar intervenções, procedimentos de gestão e a concepção de novos projetos.

Assim, a pesquisa que originou esse artigo se propõe a realizar uma Avaliação Pós-Ocupação em uma universidade federal, usando com estudo de caso dois edifícios relativamente recentes, construídos no contexto de expansão da Universidades Federais. Espera-se criar subsídios para a melhoria dos processos de gestão e manutenção dos casos, para auxiliar na proposição de 
intervenções nesses edifícios, como também para fomentar os projetos futuros similares desta e de outras instituições, considerando o grande número de universidades públicas no país e seu parque de edifícios.

Nesse artigo, se propõe a análise de um dos resultados parciais desses estudos, no que se refere a aplicação de instrumentos de avaliação dos usuários questionários e entrevistas - em um dos estudos de caso - que possibilitou identificar especificidades da percepção da comunidade no desempenho do edifício.

\section{METODOLOGIA}

O trabalho faz parte de uma pesquisa de mestrado, que visa aplicar a APO em edifícios de uma universidade federal no estado de São Paulo. Trata-se de pesquisa experimental, que utiliza a análise de estudos de caso como método de desenvolvimento, buscando um diagnóstico inicial das construções avaliadas.

Foca-se na adequação do edifício ao seu uso e na satisfação da comunidade, por meio de alguns instrumentos consagrados para aferir a percepção do usuário de um desses estudos: questionários e entrevistas.

Os questionários foram elaborados, divididos em subgrupos (discentes, docentes e técnicos administrativos). A aplicação foi remota e eletrônica, sendo os instrumentos disponibilizados via plataforma on-line Googleforms, enviando-se links por e-mail. A participação foi voluntária, de amostragem não probabilística (MATTAR, 2001), mas considerada adequada para os objetivos da pesquisa.

As entrevistas foram realizadas com "pessoas-chave", importantes no contexto de projeto, construção e, principalmente, gestão e operação do edifício, são elas: arquitetos da instituição que participaram da concepção do projeto; profissionais que atuam na gestão de infraestrutura do edifício (engenheiro e arquiteto); e diretor acadêmico do campus. Foram entrevistas semiestruturadas (RHEINGANTZ et al, 2009), com roteiros prévios, mas com certa liberdade do entrevistado em tratar dos assuntos, complementar com comentários, alterar a ordem das perguntas, etc., foram gravadas e transcritas.

Em ambos os casos, os documentos - roteiro das entrevistas e modelo dos questionários - foram submetidos à aprovação de Conselho de Ética via Plataforma Brasil, do governo Federal. Os participantes manifestaram concordância em colaborar com a pesquisa através de Termo de Consentimento Livre e Esclarecido (TCLE).

Depois de coletados, os dados de ambos os instrumentos foram analisados, sendo aqui apresentadas as considerações parciais dessas análises.

\section{APRESENTAÇÃO DO ESTUDO DE CASO}

O Edifício em estudo está inserido em um pequeno campus universitário (terreno de aproximadamente $21 \mathrm{mil} \mathrm{m}^{2}$ ) onde existem outras construções, com programas complementares, ambos atendendo à mesma Escola-como pode ser verificado na Figura 1. 


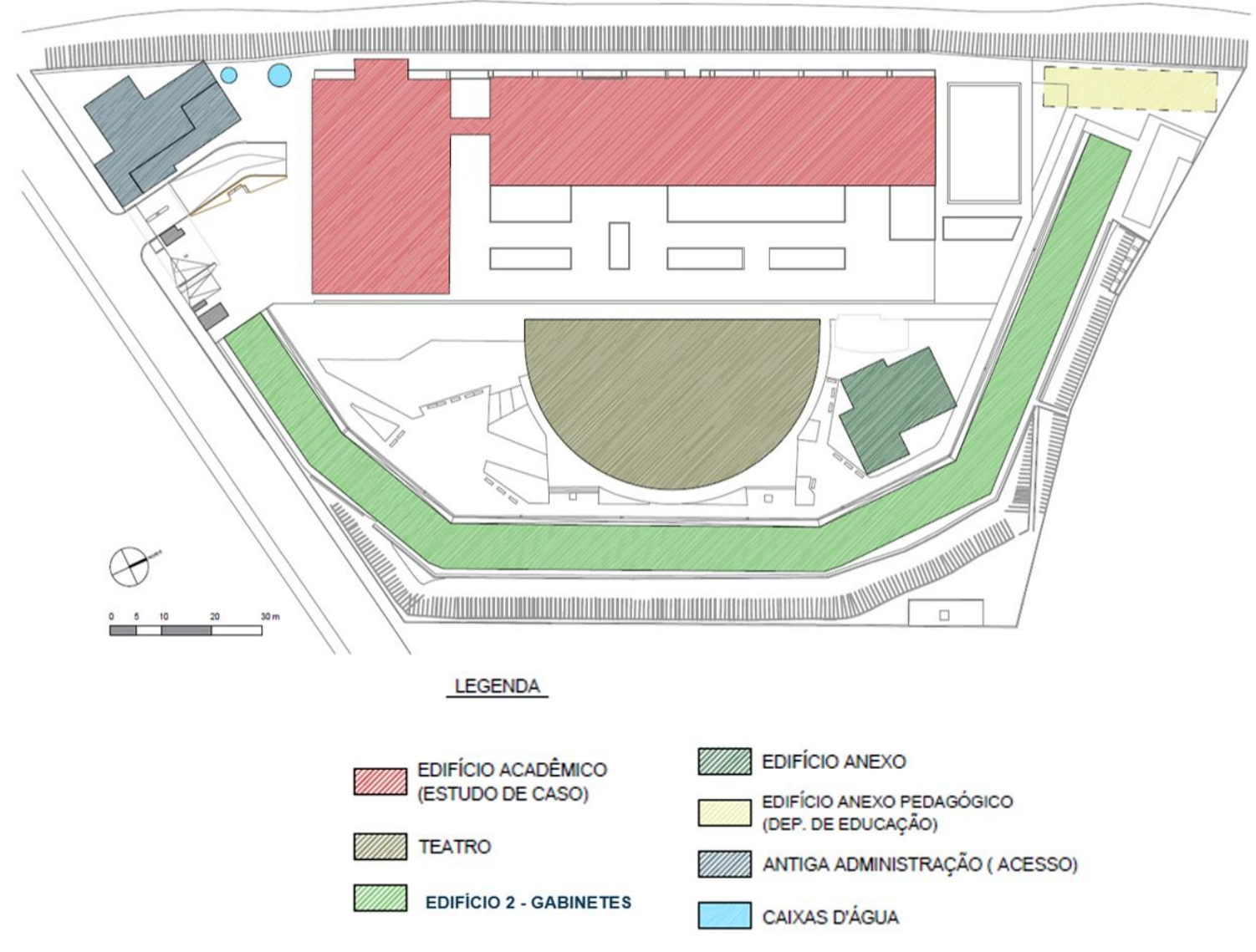

Figura 1 - Esquema de implantação do campus do estudo de caso Fonte: Autores (2018)

O edifício em estudo foi inaugurado em 2016, possuindo cerca de $18 \mathrm{mil} \mathrm{m}^{2}$, e cinco andares (subsolo, térreo e mais três pavimentos). Pode ser dividido em bloco A (que abriga a biblioteca no primeiro e no segundo andar, e um conjunto de laboratórios de pesquisa no terceiro) e bloco B - basicamente composto por salas de aula do $1^{\circ}$ ao $3^{\circ}$ andar e algumas salas de pesquisa e apoio didático). Os dois blocos se conectam em todos os andares, através de uma passarela de passagem. No térreo, o programa abrange restaurante universitário, pátios cobertos e um pequeno auditório. No subsolo estão o estacionamento e áreas técnicas.

As Figuras 2 e 3 exemplificam a distribuição do programa (sendo o primeiro pavimento apresentado como "tipo", havendo pouca variação de programa em relação ao segundo e ao terceiro pavimento).

O edifício possui sistema estrutural principal em concreto armado préfabricado, sendo a cobertura em laje impermeabilizada (pavimento técnico). O sistema de vedações é principalmente composto de blocos de concreto, mas também divisórias de gesso acartonado internamente, principalmente entre salas de aula e laboratórios. A fachada, revestida em fulget, possui esquadrias de alumínio protegidas por um brise metálico.

A instituição em questão oferece cursos da área de ciências humanas, de graduação e pós-graduação. Serve uma população de cerca de 4 mil usuários, sendo 3.600 alunos, 240 docentes e 90 técnicos administrativos, além de terceirizados e população esporádica (eventos, atividades de extensão). 

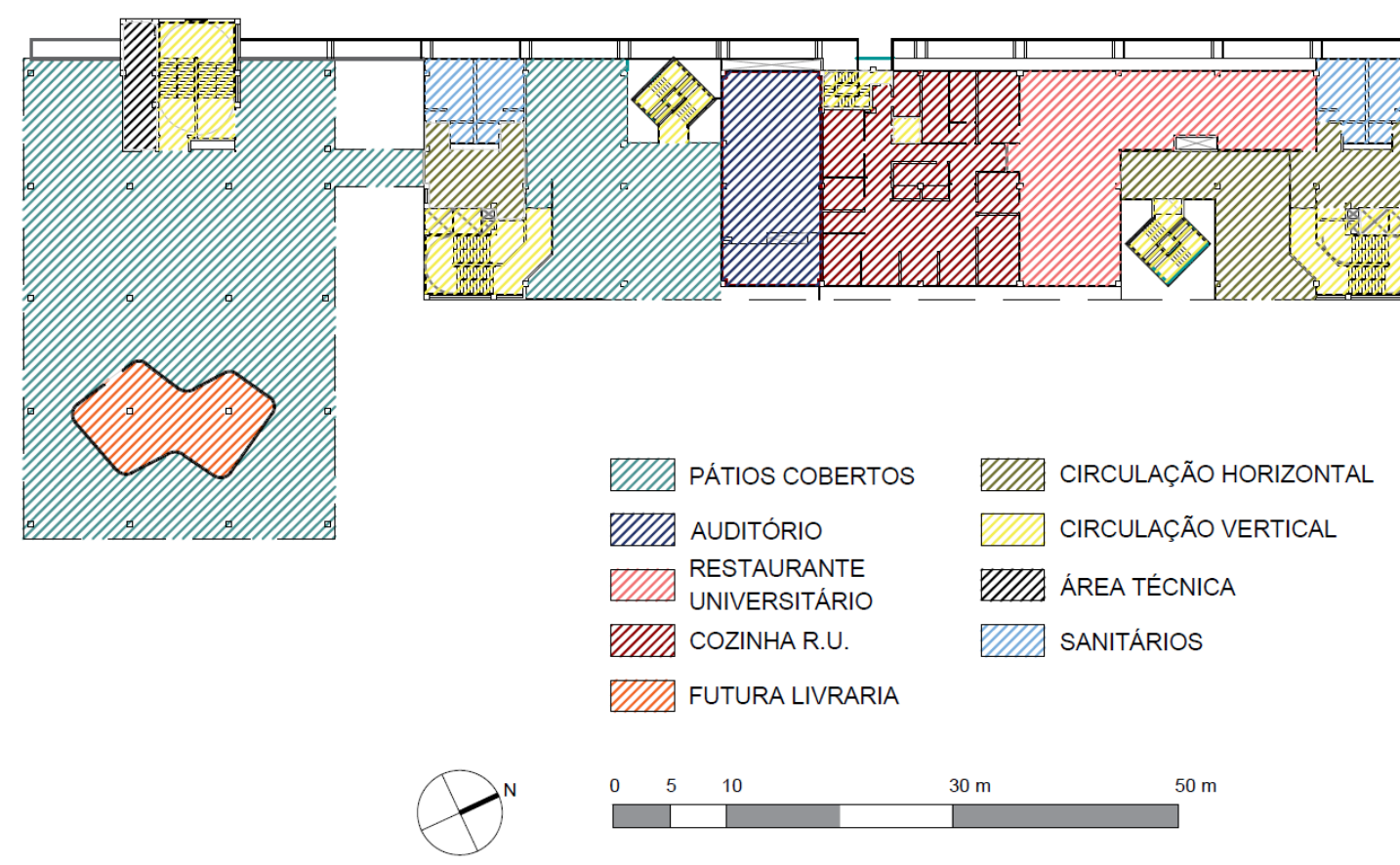

Figura 2 - Planta esquemática do térreo -

Fonte: Autores (2018)
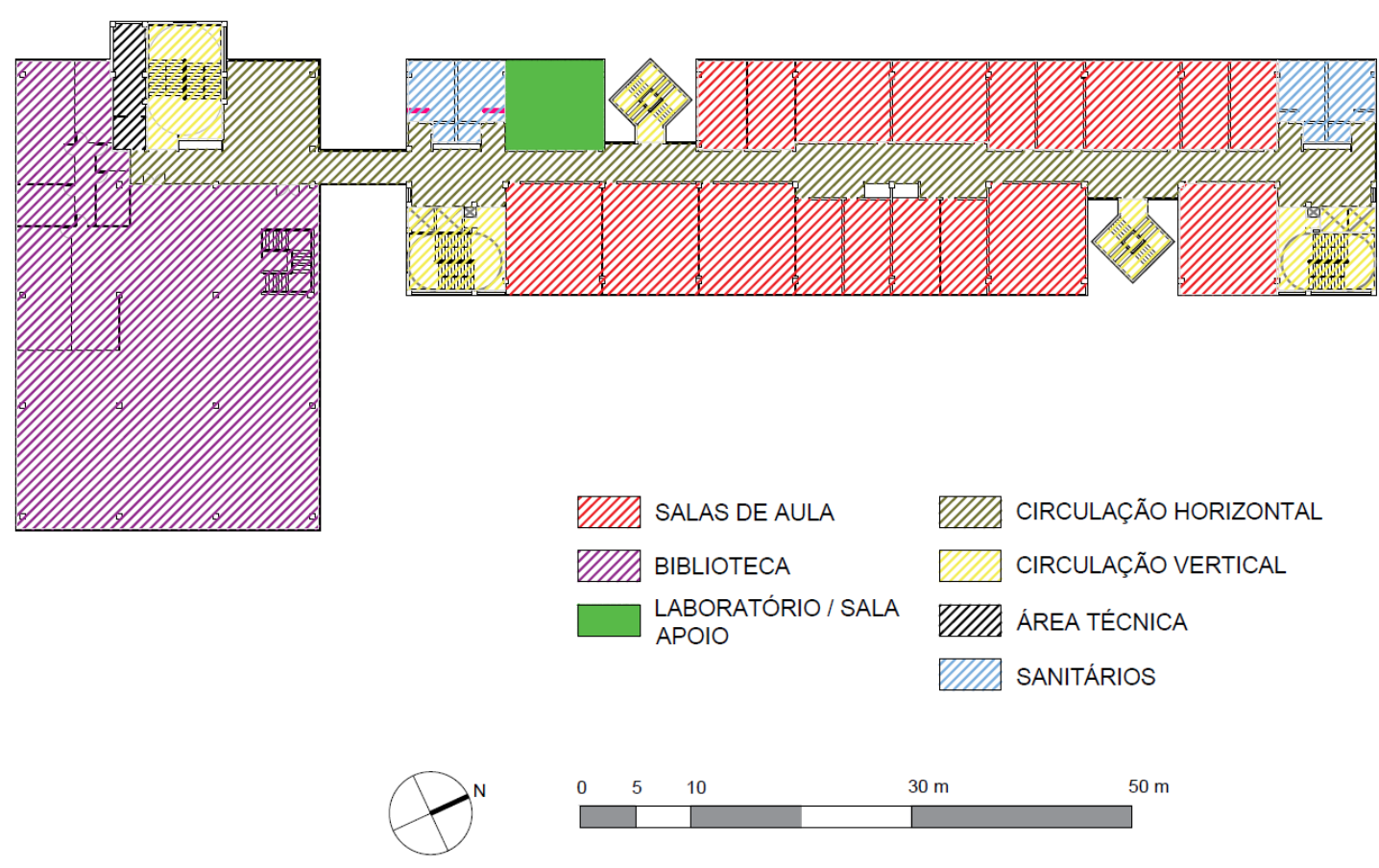

Figura 3 - Planta esquemática do primeiro pavimento Fonte: Autores (2018)

O edifício foi construído em um contexto de expansão das universidades públicas no país (parte do Programa REUNI), como unidade definitiva de uma escola que anteriormente funcionava em instalações provisórias, alugadas ou adaptadas, realidade comum na instituição em estudo. 


\section{RESULTADOS PARCIAIS}

Para os questionários aplicados, houve 231 respostas válidas do corpo discente (6,4\% do total de alunos); 17 respostas válidas no questionário do corpo docente $(7,4 \%$ do total); e 13 respostas de técnico administrativos $(14,13 \%$ do total). As questões dividiam-se em 4 blocos, sendo o primeiro tratando da caracterização dos respondentes (idade, gênero, curso, etc.); o segundo com questões sobre locomoção e acesso; já o terceiro (e maior bloco) versava sobre a qualidade do ambiente construído (conforto, dimensões, equipamentos, etc.). Por fim, os questionários foram concluídos com um bloco sobre impressões gerais, que buscava fazer um balanço dos resultados. Além das questões objetivas, com escala de valores (péssimo, ruim, bom e ótimo), a maior parte das questões permitia comentários em respostas abertas.

Dos resultados dos questionários analisados, foi possível perceber que:

- Boa parte da comunidade não mora no município onde está implantado o estudo de caso, sofrendo e se queixando da localização do campus e do deslocamento necessário para chegar ali.

- Os três grupos - alunos, professores e técnicos - possuem avaliações semelhantes para a maior parte das perguntas, apesar de certa variação - principalmente em locais de uso mais intenso de um grupo específico (por exemplo, docentes eram questionados também sobre dimensionamento e conforto de áreas de pesquisa e salas de reuniões; Os técnicos, além desses dois semelhante aos docentes, também sobre áreas técnicas e depósitos).

- Questões como dimensionamento dos espaços, funcionalidade, acessibilidade, e aspectos construtivos foram bem avaliadas, com poucas queixas.

- O conforto ambiental tem avaliação satisfatória, com ressalvas principalmente para questões de desempenho acústicos nas salas de aula e de controle de conforto térmico (controle de ar condicionado fora das salas ou brises de difícil manuseio), que receberam as críticas mais generalizadas.

- O conjunto de ambientes denominado "Pátios cobertos" foi frequentemente o que recebeu a pior avaliação, mostrando um desempenho insatisfatório nesse tipo de espaço (áreas de convivência, lazer, descanso).

No bloco de impressões gerais, os respondentes atenderam ao seguinte questionamento: Em linhas gerais, como o(a) senhor(a) se sente em relação ao Edifício? As respostas das 3 categorias são apresentadas na tabela e nos gráficos a seguir, também com a soma das respostas das categorias, para uma avaliação geral.

Percebeu-se que o campus, mesmo com as queixas e possibilidades de melhoria, foi bem avaliado por seus usuários - as avaliações positivas somam mais de $3 / 4$ das opiniões dos respondentes. A categoria com maior grau de insatisfação é a dos docentes - $23,5 \%$ e a com menor grau são os técnicos administrativos $-15,4 \%$. 
Tabela 1 - Resultados da questão sobre satisfação geral - todos os grupos

\begin{tabular}{|c|c|c|c|c|}
\hline Conceito & DISCENTE & DOCENTE & TAE & $\begin{array}{l}\text { Do total (261 } \\
\text { respondentes) }\end{array}$ \\
\hline Muito insatisfeito & $2,2 \%$ & $0,0 \%$ & $0,0 \%$ & $1,9 \%$ \\
\hline Insatisfeito & $18,2 \%$ & $23,5 \%$ & $15,4 \%$ & $18,4 \%$ \\
\hline Satisfeito & $66,7 \%$ & $47,1 \%$ & $53,8 \%$ & $64,8 \%$ \\
\hline Muito satisfeito & $10,4 \%$ & $23,5 \%$ & $23,1 \%$ & $11,9 \%$ \\
\hline $\begin{array}{c}\text { Prefere não } \\
\text { responder }\end{array}$ & $2,6 \%$ & $5,9 \%$ & $7,7 \%$ & $3,1 \%$ \\
\hline
\end{tabular}

Fonte: Elaborado pelos autores (2018)
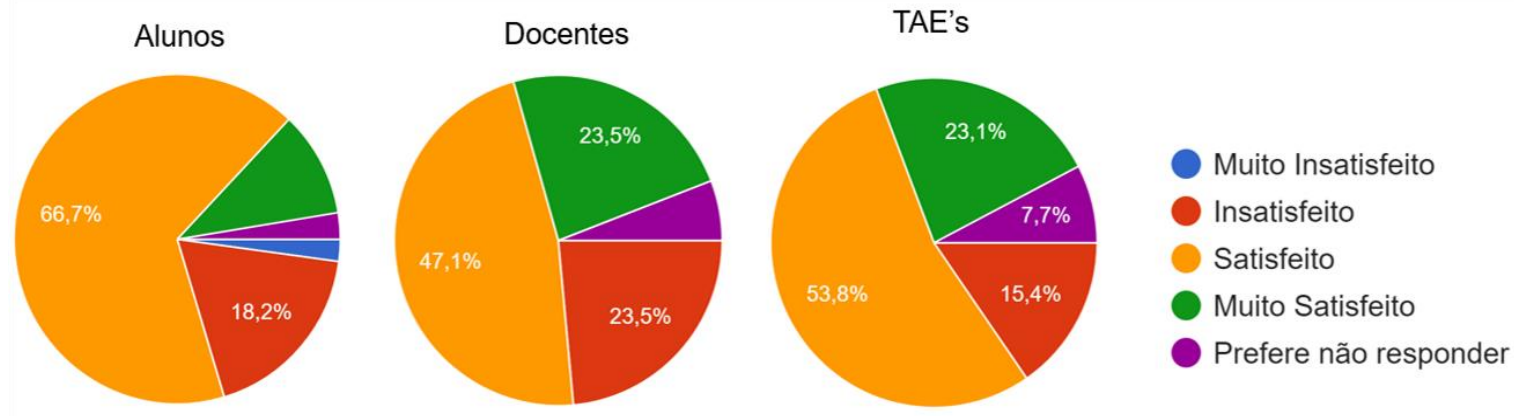

Figura 1 - Gráfico com resultados da questão sobre satisfação geral Fonte: Elaborada pelos autores (2018)

A percepção dos participantes das entrevistas condizia com essa realidade de satisfação do usuário em geral. De acordo com as "pessoas chave" principalmente as que atuavam diretamente no campus onde está o estudo de caso - foi de que a comunidade estava satisfeita, embora haja pontos de concordância a serem melhorados. Uma das principais motivações para essa sensação de satisfação seria, na opinião dos entrevistados, a situação precária anterior da instituição, que vinha de um prédio alugado que não atendia bem suas necessidades.

Na sequência, os respondentes foram questionados sobre o principal ponto a ser melhorado no edifício. Essa foi uma pergunta aberta, permitindo a resposta discursiva - mas as referências foram agrupadas e tabeladas por similaridade. A Tabela 2 apresenta esses resultados para o corpo discente, que possuía o maior número de respostas. Como é possível verificar, para eles (embora as queixas sejam semelhantes nos demais grupos) se destacaram, com ampla maioria, referências à melhoria das condições ou na oferta de espaços de convivência e lazer - das 231 respostas, 109 mencionavam esse ponto (47,2\%).

Nesse último quesito, podemos citar como falhas relatadas em relação aos pátios cobertos a ausência de mobiliário adequado (bancos, mesas, sofás) para caracterizar um espaço de convivência, além de reclamações a respeito de desconforto térmico (correntes de vento frias), ausência de vegetação, e falta de espaço para atividades estudantis como assembleias.

Os comentários sobre outros assuntos foram mais equilibrados, com menores percentuais de menção. 
Já em relação às entrevistas, para as "pessoas chave" entrevistadas, que possuíam um envolvimento diferente com a realidade da instituição, foi frequente a referência ao impacto das questões de gestão e operação do edifício na qualidade do espaço: a consciência dos processos burocráticos de intervenção, da expansão rápida e do acúmulo de demandas de infraestrutura; dos obstáculos para manutenção e da constante necessidade de modernização. Para eles, o principal problema do campus não estava no desempenho do edifício em si, mas na falta de espaço - surgindo uma necessidade de construir outro edifício para abrigar demandas improvisadas.

\section{Tabela 2 - Pontos mais comentados entre os respondentes como melhorias prioritárias - corpo discente}

\begin{tabular}{|c|c|c|c|}
\hline Class. & Melhoria Prioritária & $\begin{array}{c}\mathbf{N}^{\circ} \text { de } \\
\text { relatos }\end{array}$ & $\begin{array}{c}\text { Porcentagem em } \\
\text { relação ao total (231 } \\
\text { respondentes) }\end{array}$ \\
\hline $\mathbf{1}$ & $\begin{array}{c}\text { Melhorias nas condições ou na oferta de áreas } \\
\text { de convivência / lazer / descanso. }\end{array}$ & 109 & $47,2 \%$ \\
\hline $\mathbf{2}$ & Aumentar a oferta de áreas verdes / vegetação. & 20 & $8,65 \%$ \\
\hline $\mathbf{3}$ & Melhorar a sinalização / informação. & 17 & $7,35 \%$ \\
\hline $\mathbf{4}$ & Melhorar a acessibilidade - condições para PcD. & 15 & $6,5 \%$ \\
\hline $\mathbf{5}$ & $\begin{array}{c}\text { Prover cores, manifestações artísticas, ou outras } \\
\text { estratégias para tornar o edifício mais acolhedor. }\end{array}$ & 13 & $5,6 \%$ \\
\hline $\mathbf{6}$ & $\begin{array}{c}\text { Melhorar as condições de acessibilidade, } \\
\text { segurança e iluminação no entorno (vias). }\end{array}$ & 13 & $5,6 \%$ \\
\hline $\mathbf{7}$ & Melhorar o conforto Térmico (frio). & 12 & $5,6 \%$ \\
\hline $\mathbf{8}$ & Melhorar o conforto nas salas quanto a Mobiliário. & 12 & $5,6 \%$ \\
\hline $\mathbf{9}$ & Melhorar a acústica nas salas de Aula. & 11 & $5,6 \%$ \\
\hline $\mathbf{1 0}$ & Tornar o prédio Convidativo a comunidade & 11 & $5,6 \%$ \\
\hline $\mathbf{1 1}$ & Promover mais ambientes de estudo. & 11 & $5,6 \%$ \\
\hline
\end{tabular}

Fonte: Elaborado pelos autores (2018)

A conclusão é que o edifício atende relativamente bem o programa para o qual foi projetado, mas já está atendendo demandas além de sua capacidade.

\section{DISCUSSÕES}

Com base nos dados levantados, percebeu-se que, no geral, o edifício é satisfatório para o usuário. Como se trata de um edifício recente (menos de três anos, e já concebido para o uso universitário - situação que não é unânime na instituição, que possui muitos edifícios adaptados de outros usos, ou provisórios - o usuário que compara a situação ao contexto anterior tende a ficar mais satisfeito com o prédio. Essa foi uma percepção relatada pelos entrevistados e confirmada nos questionários.

Quanto a principal situação de insatisfação - a falta ou a má qualidade dos espaços de convivência - embora importante para todos, parece afetar 
principalmente os discentes. Seria importante uma boa oferta desses espaços para melhorar a sensação de conforto e acolhimento, tornando o prédio um estimulador da vida universitária - colaborando para a integração e troca de experiências. Sanoff e Walden (2012) destacam em suas pesquisas sobre edifícios escolares, que o ambiente construído atua como um "terceiro professor" para os alunos (além do docente e do aprendizado entre os pares), contribuindo para o desempenho acadêmico e para a permanência estudantil. Os espaços didáticos têm falhas de desempenho, mas são bem avaliados - caberia então essa maior atenção aos espaços onde a comunidade passa seus intervalos, locais de interação e de troca de conhecimento informal, propícios também ao desenvolvimento de outras atividades estudantis, extensão e interação com a vizinhança.

A situação ganha mais destaque considerando que boa parte da comunidade mora distante do edifício e faz um percurso longo e cansativo, para estar ali. O provimento de espaços aconchegantes, que tornem a experiência no ambiente mais agradável, melhorando a relação do usuário com o edifício, se torna essencial para a vida acadêmica.

Soluções para aspectos técnico-construtivos também precisam ser buscadas, em relação à outras queixas dos questionários, e que afetam o desempenho do edifício. Os entrevistados têm uma percepção melhor dessas questões, possivelmente pelo acompanhamento dos casos e por já terem recebido relatos e queixas semelhantes, uma vez que atuam na gestão do edifício. Destacam-se pontos como a necessidade de melhorias no isolamento acústico nas salas de aula e o controle térmico. Também soluções para manifestações patológicas comuns como fissuras, falhas de drenagem e de impermeabilização. A comunidade geral apresentou pouca sensibilidade à essas manifestações patológicas, que foram mais destacados pelos profissionais da área de construção entrevistados. No entanto, quando há falhas, elas podem passar ao usuário a sensação de um edifício mal construído, acrescidos aos riscos de deterioração dos sistemas construtivos dele.

Além de soluções paliativas, é importante incorporar cuidados a esse respeito nos projetos de intervenção e de novos edifícios, para evitar a perpetuação de problemas.

Percebeu-se então que, mesmo com manifestações patológicas e ocorrências encontradas, a manutenção e conservação do edifício é bem avaliada, mostrando eficiência da equipe de gestão em minimizar ocorrências decorrentes de projeto e execução, não sendo essas questões preponderantes para a percepção do usuário.

Como resultados da pesquisa, em relação às análises, também foi possível perceber a importância da coleta de informações de diversas fontes, inclusive entre padrões de usuários distintos - por mais que os profissionais de gestão tenham certa percepção sobre os problemas do edifício, ficou claro que a atenção e a priorização de demandas é diferente entre os entrevistados e os respondentes do questionário - as pesquisas de satisfação do usuário podem então, ajudar o gestor a qualificar melhor suas demandas, a quantificar e definir prioridades de intervenção, tendo em vista aquelas mais citadas pela comunidade pesquisada. 


\section{CONSIDERAÇÕES FINAIS}

Para o usuário, o edifício é bem avaliado, mesmo com falhas construtivas percebe-se que a comunidade é menos sensível à percepção de manifestações patológicas que foram verificadas em vistorias, porém mais sensivel á falhas de conforto e aos pontos de demanda não atendidos no programa arquitetônico. Os dados são importantes para a proposição de melhorias no estudo de caso, mas também devem ser considerados como ponto de partida em outros projetos. Nesse sentido, a avaliação se mostrou benéfica, atingindo os resultados esperados, que precisam ser trabalhados nas próximas etapas. Quando finalizada, a avaliação poderá fornecer a instituição um balanço do desempenho do edifício construído, auxiliando-a no desenvolvimento de seus futuros projetos e intervenções.

\section{AGRADECIMENTOS}

Aos participantes (entrevistados e respondentes) que colaboraram com a pesquisa, bem como a instituição que permitiu o estudo de caso.

\section{REFERÊNCIAS}

BRASIL. Ministério da Educação (MEC). Recursos dobram em oito anos nas universidades federais. Notícia publicada no portal do Ministério da Educação em 25 de fevereiro de 2011 . Disponível em: http://reuni.mec.gov.br/noticias/37noticia-destaque/902-recursos-dobram-em-oito-anos-nas-universidadesfederais. Último acesso em 12.05.2019.

MARTINS, R. M. P.; ANDERY, P. R. P.; STARLING, C. M. D. Análise do processo de projeto em obras de readequação predial em instituição universitária pública. 15 Encontro Nacional de Tecnologia do Ambiente Construído. Maceió, 2014. Disponível em: <http://www.infohab.org.br/entac2014/artigos/paper_192.pdf>. Acesso em: 01 fev. 2019.

MATTAR, F. N. Pesquisa de Marketing - Edição Compacta. São Paulo: Editora Atlas, 2001.

ORNSTEIN, S. W. Acompanhamento continuado - Avaliação pós-ocupação identifica erros e facilita a criação de produtos com níveis de desempenho de acordo com as expectativas do mercado. Revista Téchne, São Paulo, n. 177, p. 18-21, dezembro de 2011 . Entrevista concedida à Ana Paula Rocha.

RHEINGANTZ, P. A.; AZEVEDO, G.; BRASILEIRO, A.; ALCANTARA, D.; QUEIROZ, M. Observando a Qualidade do Lugar: Procedimentos para Avaliação PósOcupação. Rio de Janeiro, Universidade Federal do Rio de Janeiro, Faculdade de Arquitetura e Urbanismo, Programa de Pós-Graduação em Arquitetura Coleção PROARQ, 2009.

SANOFF, H.; WALDEN, R. School Environments. In: CLAYTON, S.D. The Oxford Handbook of Environmental and Conservation Psychology. Nova York, Oxford University Press, 2012, p.276 -294. Publicação digital disponível em: <https://www.researchgate.net/publication/234625948_School_Design>. Acesso em: 26 nov. 2017. 